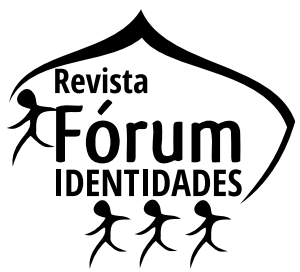

\title{
LITERATURA E HISTÓRIA EM A CASA DAS SETE MULHERES, DE LETICIA WIERZCHOWSKI'
}

\author{
LITERATURE AND HISTORY IN \\ LETICIA WIERZCHOWSKI'S A CASA \\ DAS SETE MULHERES
}

\begin{abstract}
Jhonatan Zati
Resumo: O romance "A casa das sete mulheres" foi publicado em 2002 pela gaúcha Letícia Wierzchowski (1972) e tem em seu pano de fundo importante episódio da história do Rio Grande do Sul: a Revolução Farroupilha (1835-1845). Enquanto poderosos homens do Rio Grande do Sul como Bento Gonçalves tentam se esquivar de taxas alfandegárias abusivas impostas pelo império, sete mulheres da família de Bento, que são Manuela, D. Ana, Caetana, Rosário, Maria Manuela, Mariana e Rosário, se encontram numa estância, enquanto esperam por seus maridos, filhos, irmãos e escrevem suas participações à margem da guerra, com seus anseios, sonhos e particularidades. O que a literatura traz de diferente para o conhecimento de mundo não é a visão de um dos lados que combateram na guerra, mas sim o lado que ficou de fora, sem participação direta: as mulheres. Essa atitude por parte das mulheres escritoras em ressaltar o olhar feminino na literatura provém das últimas décadas do século XX, com o movimento da Crítica Feminista, aliada a um novo olhar dos historiadores sobre o discurso literário.
\end{abstract}

Palavras-chave: Mulheres na Literatura. Literatura e História. A Casa das Sete Mulheres. Letícia Wierzchowski.

\begin{abstract}
The novel A Casa das Sete Mulheres was published in 2002 by writer Letícia Wierzchowski (1972) and has an important episode in the history of Rio Grande do Sul, a Brazilian state as its background: Revolução Farroupilha (1835-1845). While powerful men from Rio Grande do Sul, a southern Brazilian state, like Bento Gonçalves, try to avoid abusive customs duties imposed by the Emperor, seven women from his family are locked up in a resort, patiently waiting for their husbands, children, and siblings and writing their insights whilst on the edge of the war, with their yearnings, dreams and most intimate thoughts and wishes. This novel, in particular, brings not the widely known "male warrior" point of view, but the side that was left without direct participation: those seven women's. This change of perspective from female writers highlight the feminine gaze in literature that comes from the last decades of the twentieth century with the Feminist Criticism, also applied to a new look of historians towards literary discourses.
\end{abstract}

Keywords: Women in Literature. Literature and History. A Casa das Sete Mulheres. Letícia Wierzchowski.

\footnotetext{
${ }^{1}$ Artigo recebido em 15 de novembro de 2020 e aceito em 10 de fevereiro de 2021.

2 Participante do Programa de Pós-Graduação em Educação da Universidade Federal de Alfenas (UNIFAL-MG). Ex-membro do Grupo de Pesquisa em Estudos Hispânicos da Universidade Federal de Alfenas (UNIFAL-MG). ORCID: https://orcid.org/0000-0001-7588-1699. E-mail: jhonatanzati@gmail.com.
} 


\section{Introdução}

O gênero literário que hoje conhecemos como romance histórico tem como uma de suas características reaver o passado através da releitura da história e do resgate das figuras do passado, as legendárias e as marginalizadas pelo discurso historiográfico. Este artigo versa sobre o entrelaçamento de literatura e história no romance "A casa das sete mulheres", publicado em 2002 pela gaúcha Letícia Wierzchowski (1972).

Como uma narrativa histórica, o seu tema é um importante episódio da história do Rio Grande do Sul: a Revolução Farroupilha, que aconteceu entre os anos de 1835 e $1845^{3}$. No Brasil do século XIX, diversas foram as lutas contra a Monarquia, a favor da instauração da República. Nesse contexto histórico encontramos poderosos estancieiros do Rio Grande do Sul, como Bento Gonçalves, que tentam se esquivar de taxas alfandegárias abusivas, mas a narrativa de Wierzchowski se volta, principalmente, para as sete mulheres da família de Bento (Manuela, D. Ana, Caetana, Rosário, Maria Manuela, Mariana e Rosário) que se encontram na estância da família, enquanto esperam por seus maridos/filhos/ irmãos e escrevem suas participações à margem da guerra, com seus anseios, sonhos e particularidades.

O que a literatura traz de diferente para o conhecimento de mundo não é a visão de um dos lados que combateram na guerra (vencedor ou vencido), mas sim, o lado que ficou de fora, sem participação direta: as mulheres. Essa atitude por parte das mulheres escritoras em ressaltar o olhar feminino provém das últimas décadas do século XX, com o movimento feminista ocorrido no final dos anos 1960, aliada a um novo olhar dos historiadores sobre a História e suas versões.

Antes desse contexto, e principalmente com o movimento iluminista no século XVII que fez com que a História ganhasse o status de ciência, a História era a única área do conhecimento que tinha a autoridade de definir a versão dos fatos passados. Sobre o movimento separatista do Rio Grande do Sul, Gonçalves (2007, p. 13) fez a seguinte declaração: “É importante notar que a historiografia tradicional sobre a Guerra dos Farrapos em geral se preocupa com facetas diversas da revolta, em especial as questões militares e políticas". Assim, como sendo um dos veículos responsáveis pela difusão dos valores e da visão de mundo da sociedade patriarcal, a História fez com que a também chamada de Revolução Farroupilha fosse tratada até então da maneira que era imposta, mais ortodoxa, garantindo ao homem que vai à batalha a - única - figura heroica daquele episódio (assim como acontece com tantos outros), esquecendo que existiram mulheres que também agiram direta e indiretamente.

${ }^{3}$ Embora seja este o nome oficial, muitos pesquisadores e cidadãos rio-grandenses optam por se referir ao episódio como "Guerra dos Farrapos", que também aparece neste artigo. 
Benjamin (1987, p. 225) alcunha a dita "história oficial" de "história do vencedor", daquele que "vence a guerra" e, em suas "Teses sobre o conceito de história", aponta com muita pertinência que

Articular historicamente o passado não significa conhecê-lo "como ele de fato foi". Significa apropriar-se de uma reminiscência, tal como ela relampeja no momento de um perigo. Cabe ao materialismo histórico fixar uma imagem do passado, como ela se apresenta, no momento do perigo, ao sujeito histórico, sem que ele tenha consciência disso (BENJAMIN, 1987, p. 225).

Assim, a exigência fundamental de Benjamin é escrever a história a contrapelo, ou seja, do ponto de vista dos vencidos - contra a tradição conformista do historicismo alemão cujos partidários entram sempre "em empatia com o vencedor".

Portanto, a discussão tem início em um questionamento: Quais são os elementos que tornam pertinente a leitura de "A casa das sete mulheres"? A resposta é clara: não se trata tão somente da história do "vencedor", o que já seria bastante atraente, mas tampouco se trata da história do "vencido", igualmente cativante. Aliás, ambos os lados foram explorados por historiadores. O ponto é que, como outros romances contemporâneos, esse trata de personagens que são esquecidas, se não negligenciadas pela história: as mulheres dos combatentes e suas lutas particulares, anseios, dúvidas e pensamentos. O fato de ter sido escrita por uma mulher deixa a obra ainda mais interessante.

\section{Literatura e História}

A História e a Literatura caminharam juntas desde os primórdios. $\mathrm{Na}$ Antiguidade, Aristóteles limitou o campo de atuação de cada uma delas - que ao historiador caberia tratar do que aconteceu e ao literato o que poderia ter ocorrido. Após a ascensão da História como ciência por volta do século XVIII, uma parte da literatura modificou o modo como passaria a tratar a história, surgindo o que hoje se conhece como "romance histórico", segundo a nomenclatura dada por Lukács (1977).

Segundo o estudioso, o romance histórico teve seu início no século XIX com os romances a partir das obras de Walter Scott e esse gênero narrativo na América Latina, nessa época, se modela ao padrão europeu. Contudo, em meados do século XX, os latino-americanos reinventam a narrativa histórica, sendo nomeado por vários críticos literários como "novo romance histórico" como Fernando Aínsa (1991) e Seymour Menton (1993), cuja classificação utilizaremos neste artigo, ainda que outros estudiosos possam atribuir outras nomenclaturas para esse tipo de narrativa. 
Enquanto no século XIX os romances utilizavam o momento histórico como "telão de fundo" na composição de uma obra, alternados com episódios e personagens fictícios (MÁRQUEZ RODRÍGUEZ, 1991), na América Latina, em meados do século XX, a história passa a ser a protagonista dos romances e o diálogo traz, entre as duas áreas de conhecimento, a construção de novos sentidos.

Seymour Menton descreve algumas características do novo romance histórico. Destacamos, aqui, entre elas, a impossibilidade de conhecer a realidade histórica total, pois o que se tem do passado são vestígios - relatos, memórias, fotos, textos, entre outros - que são interpretados conforme a ideologia da época ou das pessoas que investigam tal assunto.

Por isso, os romancistas contemporâneos reivindicam a possibilidade de oferecer uma interpretação do passado histórico, pois história e romance histórico são narrativas, ou melhor, discursos linguísticos que utilizam os mecanismos de organização textual para descreve um fato histórico. O escritor literário, contudo, consegue uma maior expressividade, pois

Lo que parece evidente, en todo caso, es que esta amplísima libertad que se ha dado el novelista contemporáneo para manejar los hechos históricos como materia de sus narraciones, tienen mucho que ver con el derecho que el mismo novelista también ha reivindicado para así, de reinterpretar los hechos históricos -sucesos y personajes- con total independencia de las interpretaciones de los historiadores, en especial de los llamados historiadores oficiales (MÁRQUEZ RODRÍGUEZ, 1991, p. 47)ㄴ․

Dentro desse panorama, surge "A casa das sete mulheres" (2002), de Letícia Wierzchowski, um romance que por meio de uma narrativa híbrida, destacando a voz feminina como protagonista sobre o passado ocorrido em seu estado.

Durante o período colonial, o contato dos estados do Brasil com a Corte Portuguesa era bastante estreito, e mesmo após a declaração da Independência, que se deu em 1822, era a capital (Rio de Janeiro), onde a Corte residia, quem decidia tudo o que tinha ligação com a política econômica do país. Àquele tempo, o principal produto de exportação do país era o café (que vinha principalmente do Vale do Paraíba), e eles determinavam as leis que as demais províncias deviam seguir, inclusive no que dizia respeito a impostos (PESAVENTO, 1985). Nessas demais províncias eclodiram outras rebeliões, mas a mais célebre e uma das de maior duração foi a que se deu no estado do Rio Grande do Sul, a Revolução Farroupilha.

\footnotetext{
${ }^{4} \mathrm{O}$ que parece evidente, em qualquer caso, é que essa ampla liberdade conferida ao romancista contemporâneo para tratar os fatos históricos como o tema de suas narrativas tem muito a ver com o que o próprio romancista também afirmou de fazer, reinterpretando eventos históricos, eventos e personagens com total independência diante dos historiadores, especialmente dos chamados historiadores oficiais (MÁRQUEZ RODRÍGUEZ, 1991, p. 47).
} 
O Rio Grande do Sul se demonstrava contra a centralidade do Sudeste e o seu produto de exportação, uma vez que o foco estava na criação de gado e na fabricação de charque, ou seja, havia a alegação de que essa centralidade prejudicava os interesses particulares da República Rio-Grandense, proclamada no ano seguinte (1836).

Após dez anos de luta, a guerra terminou com algumas das reivindicações daquela República sendo atendidas e com a assinatura da Paz de Ponche Verde. A revolta nos deu algumas das mais célebres personagens históricas do Brasil, com algumas delas depois enraizadas no imaginário popular, tais como Anita e Giuseppe Garibaldi, Manuela e, principalmente Bento Gonçalves, o líder.

Após esse breve panorama de um complexo episódio da História, a questão se volta para a maneira como Wierzchowski utilizou o discurso histórico em seu romance, não para reforçar a versão apresentada pela historiografia, mas sim, apresentar uma nova possibilidade de leitura, por um viés que não era contemplado pelos discursos históricos: o olhar feminino.

As narrativas histórica e ficcional se assemelham naquilo que elas são constituídas: o discurso. Trouche (2006) discorre brilhantemente sobre o assunto e ao que ele tange, atribuindo a diversos fatores o interesse da "reinvenção" da narrativa histórica. Entre eles, estão a relativização e a abrangência do significado da verdade consumada pela História, aliados à responsabilidade que as construções sociais têm nessa consumação.

Para o autor, também estão ligados a essa linha o nosso natural interesse pelo passado, a nossa natural busca por referências e o nosso espírito auto questionador, o que alimenta a ideia de que encontraremos respostas para o nosso presente e previsões para o nosso futuro revisitando o passado e, com o passar do tempo, fez com que a Literatura passasse a fazer uso de recursos que garantissem a coerência e a verossimilhança e não mais a mera legitimidade daqueles escritos, fazendo a passagem para o surgimento de conceitos de romance (TROUCHE, 2006, p. 35).

\section{O olhar feminino como identidade na Literatura}

A publicação de "A casa das sete mulheres" é deveras recente, considerando que se deu no início do século XXI. No entanto, remete a tempos mais longínquos, por meio de um viés que trabalha com o passado e as intimidades de suas personagens (sobretudo as femininas) e, sobre isso, Lúcia Castello Branco, em seu livro "O que é a escrita feminina" (1991, p. 30), afirma que as mulheres, por décadas, se dedicaram a escrita autobiográfica (em um viés memorialístico) pois, “(...) historicamente confinadas ao universo do lar, ao interior da casa, elas teriam encontrado nesse tipo de escrita o veículo ideal para a expressão de sua vida íntima, seus desejos, suas fantasias". 
É essa a ideia que interessa a este trabalho. Há pouco foi apresentado um panorama geral do que se tratou a Revolução Farroupilha e um pouco da discussão acerca daquilo sobre o que a História dita oficial trata. Há muito tempo, tem-se elo senso comum imagens moldadas de figuras heroicas mitificadas e quase irrepreensíveis, muito similares, guardadas as devidas proporções, às figuras dos heróis da mitologia.

O objetivo deste trabalho não é o de revogar nem tampouco o de refutar essas ideias já pré-estabelecidas, mas o de mostrar que há (e sempre houve) um outro lado da história que foi silenciado: o ponto de vista das mulheres que fizeram parte daquele episódio. Seria como um acréscimo às contribuições que a História nos dá.

Voltando sobre o tema da escrita feminina, Castello Branco (1991, p. 14) aponta para que, quando despontavam autoras femininas, elas focavam em assuntos que lhes couberam falar àquela época, como a maternidade, a casa ou a infância, e praticamente nunca sobre os negócios, as guerras, a vida urbana e coisas externas ao "eu". E, logo, segundo ela,

não é difícil afirmar que as mulheres não escreviam textos épicos porque não iam às guerras, que sua preferência pelo gênero memorialístico ou autobiográfico se deve a seu profundo conhecimento dos universos do lar e do eu, próprios à criação de uma escrita intimista. (CASTELLO BRANCO, 1991, p. 14).

Trata-se, portanto, de um romance muito rico, tanto em seu conteúdo quanto em sua estrutura, pois consegue propor uma nova leitura histórica e consegue captar, ao mesmo tempo, o olhar feminino daquele período, que como aponta Zolin (2005, p. 56) sobre a escrita feminina, é feito de "minúcias, de banalidades, de desvios, de multiplicações dos sentidos minúsculos".

Isso pode ser visto ao longo de toda a narrativa. Muitas vezes, o cenário é minuciosamente descrito pela narradora Manuela, que narra a guerra, narra a vida nova na estância de D. Ana, narra o que acontece com os familiares a sua volta e se insere no contexto de guerra, mas ainda se mostra doce e romântica ao longo da redação de seus diários pessoais, seção na obra chamada de "Cadernos de Manuela".

Em muitos momentos, podemos perceber que a figura feminina de início é reduzida aos papéis comuns para a época. Enquanto o homem luta pelos seus interesses, a mulher está inicialmente presa às futilidades que a sociedade permitia que conhecesse, tais como quando

[...] as moças trataram de falar de coisas alegres, pois para elas a temporada na estância era nada mais do que férias, logo deveriam voltar para Pelotas, para os chás domingueiros com as amigas de bordado, e para os bailes. Isso mesmo, para os bailes, que elas tanto desejavam (WIERZCHOWSKI, 2005, p. 30). 
As novas moradoras da estância de D. Ana inicialmente passavam seus dias no conforto do lar, onde são refletidos os costumes da época, como a execução da então música popular, a leitura de livros e a relação das mulheres com o religioso.

Assim, pode se relacionar o desenvolvimento de "A Casa das Sete $\mathrm{Mu}-$ lheres" com a Crítica Literária Feminista, uma ramificação da Teoria da Literatura bastante recente, surgindo nos anos 1970, ao buscar dissolver a disparidade existente na relação homem X mulher. Zolin (2005, p. 182) diz que esse ramo da teoria "trabalha no sentido de interferir na ordem social", uma vez que se trata de uma nova maneira de se ver a História, dando um novo papel às mulheres e questionando o que foi imposto pela cultura.

Um dos propósitos principais dos debates decorridos da Crítica Literária Feminista foi derrogar os discursos instaurados pelo cânone literário em que a escrita feminina era menosprezada e a descrição das mulheres era binária: ou ela era uma megera e/ou sedutora (um modelo de mulher que não deveria ser seguido), ou era uma mulher-anjo, como um exemplo a ser imitado pelas demais. Assim, a escrita feminina passa por um processo de foi da imitação aos moldes patriarcais para a busca de uma identidade própria, na qual a mulher poderia se expressar com liberdade e colocar em questionamento a maneira como a sociedade subjugava a mulher.

Uma importante representante é Elaine Showalter que, em " A Literature of Their Own" (1986), analisa os textos de escritoras inglesas do século XIX e demonstra que o desenvolvimento da tradição seguida pelas autoras é semelhante em qualquer subcultura literária. Ela propõe uma classificação para essas fases históricas das subculturas literárias escritas por mulheres dos Estados Unidos: feminine, feminist e female.

Traduzida como "feminina", a primeira fase engloba as autoras que imitam os modelos masculinos e as tradições da literatura dominante (leia-se: masculina) e outorgam às suas personagens femininas papéis secundários. $\mathrm{Na}$ segunda, a "feminista", temos uma etapa de protesto por parte das escritoras que se insurgem contra a condição subordinada da mulher na sociedade e da sua representação na literatura, mas não conseguem se desprender completamente dos padrões da literatura dominante. $\mathrm{Na}$ última fase, muitas vezes traduzida para o português como "da Mulher", indica a busca da identidade e da autonomia feminina, na qual as mulheres encontram um conhecimento de si mesmas e dos problemas em questão e o interesse se volta para os textos escritos por elas mesmas.

Essa classificação pode ser válida para literaturas escritas por mulheres de outros países, como do Brasil. Com o surgimento dos estudos de literatura e mulher e a grande efusão de obras literárias escrita por mulheres no nosso país, 
podemos dizer que a literatura feminina brasileira se encontra na terceira fase indicada por Showalter porque encontramos muitas obras e escritoras que se voltam para marcar a identidade feminina e a reivindicar o protagonismo feminino.

No seu romance, a escritora tem como foco a situação das mulheres em um momento de guerra, demostrando, primeiramente, como teria sido a vida delas nesse contexto e, principalmente, como algumas delas tentaram romper com os padrões do patriarcalismo que eram submetidas.

Assim, inicialmente, a autora descreve com detalhes a vida e os afazeres dessas mulheres do século XIX, assinalando como as questões femininas eram inferiorizadas ao serem comparadas com os temas masculinos:

\begin{abstract}
As mulheres ocupavam-se com seus assuntos menores, seus anseios, não reles em tamanho, pois dessa delicada fímbria feminina é que são feitas as famílias e, por conseguinte, a vida; falavam dos filhos, do calor do verão, dos partos recentes; tinham um olho posto nas conversas, os risos doces, a alegria; porém, com o outro fitavam seus homens: tudo o que lhes faltasse, de comer ou de beber, do corpo ou da alma, eram elas que proviam (WIERZCHOWSKI, 2005, p. 12-13).
\end{abstract}

Algumas das sete mulheres que protagonizam o romance buscam libertar-se não somente da situação de guerra em que se encontram, mas também do patriarcado, que, assim como a batalha, as aprisiona e as deixa à deriva e frente ao que lhes sempre foi imposto.

É indiscutível a carga emocional que as histórias presentes no romance carregam, característica presente em mulheres que sofrem por amor, além do significado de ruptura com as representações oficiais da historiografia. Dito isso, temos de considerar que "se o enigma do texto está ligado a uma ruptura, a um recalcamento originário, a uma castração, à proibição do contato, pode-se afirmar que ele remete ao enigma por excelência, que é a feminilidade" (KOFMAN apud BRANDÃO, 1996, p. 21).

D. Ana, a matriarca e dona da estância onde as outras seis mulheres vivem, é uma figura peculiar, por liderar a família de maneira que parece incomum para a mulher da época, pois lidera sua casa, toma as decisões necessárias, administra sua fazenda, dá as ordens. Assim, opõe-se ao que se caracterizava então como feminino, quando se mostra a que rege o grupo.

Caetana e Maria Manuela simbolizam a figura clássica da esposa que espera pelo marido enquanto ele invade o campo de batalha. Caetana sofre, é basicamente uma mártir, que sabe de sua missão e a cumpre com muita fé. Como a personagem Manuela aponta, "as mulheres é que ficam, é que aguardam. Nove meses, uma vida inteira. (...) Como um muro, é assim que uma mulher espera pelo seu homem" (WIERZCHOWSKI, p. 72). 
Maria Manuela é uma mulher que sente saudades incessantes dos momentos com o marido e a que perde o marido na batalha. De todas as mulheres da casa, é a mais severa, ainda que doce; a que mais vela "pela moral e pelos bons costumes", sendo uma representante digna da mulher submissa de uma sociedade patriarcal que reproduz os padrões impostos, exigindo que as filhas também sejam submissas.

Manuela é a imagem da mulher ciente, que entende aquilo pelo que passa, mas não abdica de sua missão socialmente imposta: apaixonar-se pelo herói e vive a solidão por não concretizar esse amor. No caso, Giuseppe Garibaldi. Manuela tem total consciência daquilo pelo que passa, vê os problemas pelos quais a mulher passa em situação como aquela e parece ter um desejo de deixar seus escritos para a posteridade, em um avanço rumo a existência de uma Literatura. A "viúva de Garibaldi" é a mulher em um momento intuitivo. Seu amor é eterno e digno de devoção. Afronta o sistema ao recusar o matrimônio arranjado com o primo Joaquim e ao envolver-se com um "arruaceiro", mas enluta por não chegar à felicidade esperada.

Mariana apaixona-se por um mestiço, João Gutierrez, e é a figura da mulher que ainda usa o tradicional para fugir do destino que a espera. Engravida e o marido é mandado para a guerra pela mãe dela, D. Maria Manuela.

Perpétua entrega-se ao amor indo contra seus próprios princípios quando se envolve com Inácio, que perde sua mulher, que havia recebido os cuidados das mulheres da estância, para alguma doença pulmonar. Envolver-se com o homem de uma mulher conhecida e falecida parecia pecaminoso demais, contrariando a moral, a ideia do socialmente aceitável. Por fim, se entrega, mas ainda à mercê da figura masculina.

Rosário caracteriza a mulher que não suporta as feridas causadas pelo confinamento, pelo sofrer da solidão e da situação de guerra. Assim, fantasiou uma paixão que a libertava. Imaginou seu amado Estevão, idealizou-o e fez dele somente seu, em sua mente. Quando sua família percebe a gravidade de seu estado, é enviada para um convento, como acontecia com muitas mulheres. O religioso aparece numa interessante dicotomia, bastante característica do romantismo: enquanto para algumas o religioso pareça um conforto, como para Caetana, para algumas parece punitivo, como no caso de Rosário. E no convento ela falece, como se fosse para os braços de seu amado, fruto de seu sonho. Representa, para mim, a mulher que sucumbe e deixa de existir. No fim, é a sua identidade que foi aniquilada em nome da liberdade que talvez jamais encontrasse. 


\section{Conclusões Finais}

A guerra chega ao fim após dez anos. Após muitas as mortes, todas as personagens parecem mais maduras, embora calejadas pela tristeza causada pela guerra dos Farrapos. Assim, encerra-se a narrativa no ano de 1845.

Está presente na obra "A casa das sete mulheres" o fazer artístico da mulher, assim como o seu ponto de vista distinto dos discursos históricos: o lugar da mulher na guerra, com seus afazeres, suas dores, sua espera. A autora proporciona aos leitores um novo olhar sobre a sociedade da época, fortemente marcada por um patriarcado que se fazia diferente do atual, quando dá o protagonismo às mulheres, destacando a sua importância no desenvolvimento do episódio.

É notória a estreita relação que existe entre a Literatura e o povo que retrata, representa ou caminha ao lado. Portanto, cada povo construiu seu cânone baseado naquilo que toma como referência-mor, como modelo. Durante um considerável tempo cronológico, a sociedade tomou como exemplo o homem, a figura que integra valores atribuídos à masculinidade e tudo que o cidadão normativo consumiu, viveu e praticou. Enquanto o ocidente se fazia espelhado nos valores de um tempo em que o guerreiro era de simbologia hercúlea, as margens da pirâmide social estabelecem, finalmente, um cânone exclusivo que dava voz aos silenciados e não-inclusos na historiografia oficial.

Nesse cenário idílico, surge o questionamento da assertividade do termo "História", o questionamento do que tomamos como verdade. Questiona-se o papel atribuído às mulheres dentro de nossa sociedade, traçando um paralelo entre o passado e o presente, o clássico e o contemporâneo. É de grande importância a alta representação feminina na obra, uma vez que o objetivo da autora era o de dar voz a quem esse direito fora sempre negado. A autora atribui às sete mulheres, pela primeira vez, o status de protagonistas da guerra, participantes ativas, mesmo que fora dos campos de batalha, dando-as merecido crédito.

A riqueza da obra está no fato de que apresenta uma estrutura enriquecedora, que permite que, acima de tudo, tenhamos uma outra visão acerca de um acontecimento histórico. O gênero romance histórico também desencadeia uma nova perspectiva do fazer literário que aliada ao trabalho sobre a mulher na sociedade e "ser pensante" contribui para a formação intelectual e crítica literária, atribuindo-nos novos valores e conhecimento sobre a linguagem e narrativa fictícias.

Esse panorama crítico fornece ao leitor de Literatura uma visão menos segmentada do mundo à sua volta, permitindo que o pensamento se desenvolva mais livremente, uma vez que permite que essas pessoas tenham contato com o desconhecido, o não dito e faça contato com o subjugado, o marginalizado, não somente com o marginalizador. 
A construção, a suplantação de membros honorários dessa digníssima posição implica falar, por exemplo daquela mulher que escreve sobre todos os anseios que a acompanha e, sobretudo, daquele a quem nunca foi dada uma chance de um local de prestígio na literatura e todas as suas particularidades.

Portanto, falar sobre Literatura e o que dela vale a pena ser tirado algo, não se limita a falar do grande homem europeu de séculos anteriores ao nosso. A fortuna crítica dos Estudos Literários e Estudos Culturais tem se mostrado cada vez mais aberta ao diálogo com os textos produzidos à margem. Mais do que nunca é importante assumir a existência de uma "escrita feminina", por exemplo. Entende-se que no passado isso tenha significado uma subcategorização, delegando à autora um lugar de escrita supérflua e inferior, mas não se pode dizer o mesmo hoje, tempos em que reafirmar a identidade confere valor ao trabalho. Confere, de fato, identidade, que é poder e resistência.

\section{Referências}

BENJAMIN, Walter. Teses sobre o conceito de história. In: Obras escolhidas, vol. 1, Magia e técnica, arte e política: Ensaios sobre literatura e história da cultura. Tradução Sergio Paulo Rouanet. São Paulo: Brasiliense, 1987, p. 222-232.

BRANDÃO, Ruth Silviano. Literatura e Psicanálise. Porto Alegre: Editora da Universidade Federal do Rio Grande do Sul, 1996.

ESTEVES, Antonio Roberto. O romance histórico brasileiro. São Paulo: UNESP, 2010.

LUKÁCS, György. La novela histórica. Tradução Jasmim Reuter. 3. ed. México: Era, 1977.

GONÇALVES, Márcio Edimir. Liberais sim, mas sobretudo republicanos: A ideologia dos Farrapos Através do periódico “O Povo". Departamento de História da Universidade Federal do Paraná: Curitiba, 2007. Disponível em: <http://www.historia. ufpr.br/monografias/2007/2_sem_2007/marcio_edimir_goncalves.pdf $>$. Acesso em 15 jul. 2015.

MÁRQUEZ RODRÍGUEZ, Alexis. Historia y ficción en la novela venezolana. Caracas: Monte Ávila, 1991.

MENTON, Seymour. La nueva novela histórica de la América Latina, 1949-1992. México: FCE, 1993.

PESAVENTO, Sandra Jatahy. A Revolução Farroupilha. Boletim Gaúcho de Geografia, p. 101-102, n. 13, ago. 1985. Disponível em: < http://seer.ufrgs.br/bgg/article/ view/37804/24388>. Acesso em 15 jul. 2015.

TROUCHE, André. América: História e Ficção. Niterói: Eduff, 2006. 
SHOWALTER, Elaine. A literature of their own: British Women Novelists from Brontë to Lessing. Princeton: Princeton University Press, 1977.

ZOLIN, Lúcia Osana. Crítica Feminista. In: BONNICI, Thomas; e ZOLIN, Lúcia Osana. (Org.). Teoria literária: abordagens históricas e tendências contemporâneas. Maringá: Eduem, 2005, p. 211-237.

WIERZCHOWSKI, Leticia. A casa das sete mulheres. 13. ed. Rio de Janeiro: Record, 2005. 